\title{
Creating strategic alignment during the development of procurement instruments
}

Henrico Plantinga MSC

Strategic Consultant, Procurement Department, ProRail, Utrecht, the Netherlands (corresponding author: henrico.plantinga@prorail.nl)

Hans Voordijk MSc, PhD

Associate Professor of Construction Management, Department of Construction Management and Engineering, Faculty of Engineering Technology, University of Twente, Enschede, the Netherlands (Orcid:00000002-1259-9407)
André Dorée MSc, PhD

Professor of Market and Organisational Dynamics in Construction Industry, Department of Construction Management and Engineering, Faculty of Engineering Technology, University of Twente, Enschede, the Netherlands (Orcid:0000-0003-1234-4858)

It is generally acknowledged that creating strategic alignment is key to achieving good procurement performance. However, when it comes to aligning procurement instruments with an organisation's strategic goals, the literature is unclear about exactly how such alignment can be created in practice. Focusing on the process of procurement instrument development by public clients in the construction industry, this research explores how alignment with strategic goals can be created. Since procurement instrument development is portrayed in the literature as a highly intuitive and subjective process, this research examined how public clients can rationally and objectively create strategic alignment during this development process. This paper presents an action research case study on the development of a new procurement instrument. By interpreting strategic alignment as coherence in reasoning between procurement instrument design and multiple levels of strategy, it explains how several research interventions eventually resulted in creating alignment in practice. The results indicate that the rational and objective creation of strategic alignment requires that the reasoning behind procurement instrument design be made explicit and linked to the reasoning behind higher-level strategies. Since this can easily become complex, practitioners should master practical tools such as causal mapping to manage the complexity effectively.

\section{Introduction}

Creating strategic alignment is generally considered essential for achieving good procurement performance (e.g. Baier et al., 2008; Glas et al., 2017; Patrucco et al., 2019; Rodríguez-Escobar and González-Benito, 2017; Søgaard et al., 2019). The concept of strategic alignment is based on the contingency theory (Drazin and Van de Ven, 1985; Spina et al., 2016) and is used to study the consistency of, for example, procurement strategies and activities with organisational objectives (Søgaard et al., 2019).

While the general procurement literature is clear about the relevance of creating strategic alignment, it is less clear about how it can be created in practice. This situation with construction industry public clients forms the research subject of interest. Although there is abundant construction management literature on selecting the appropriate procurement approach, this seems to ignore, or only implicitly employ, the strategic alignment concept (e.g. Love et al., 2012; Naoum and Egbu, 2016; Watermeyer, 2012).

In particular, the construction management literature is unclear as to the importance of aligning procurement instruments with an organisation's strategic goals. The literature lacks both theoretical insights and knowledge of current practice about how such alignment can be achieved. This issue needs to be addressed, as this gap potentially hinders improvements to procurement performance.

This paper investigates how strategic alignment between procurement instruments and organisational goals can be created in practice. It does so by focusing on the phenomenon that public clients not only use existing procurement instruments but also develop new ones (Plantinga et al., 2019). This phenomenon is particularly significant since it suggests that public clients see a need to invest in the self-development of procurement instruments in addition to adopting instruments developed elsewhere, such as the NEC3 suite of contracts. Since this apparent need suggests a perceived opportunity to increase procurement performance, this development process is highly relevant for the public client.

However, previous research indicates that in practice, procurement instruments are often developed in a highly intuitive and subjective process, involving few theoretical or empirical considerations (Ballesteros-Pérez et al., 2015). Given this characterisation of the procurement instrument development process and the generally acknowledged need to create strategic alignment, it would seem that procurement performance could be improved by investigating how the alignment construct can be applied in this particular process. Therefore, the specific purpose of this research has been to examine how public clients can rationally and objectively create strategic alignment during the procurement instrument development process.

\section{Literature review}

Previous research has recognised the relevance of creating strategic alignment in both private (Baier et al. 2008; Rodríguez-Escobar and González-Benito, 2017) and public (Patrucco et al., 2017, 2019) procurement. The central proposition of strategic alignment is that the 
performance of an organisation is determined by the alignment or fit between two or more factors such as strategy, structure, technology or environment (Meskendahl, 2010; Schoonhoven, 1981).

Patrucco et al. (2017) propose a framework that appears to reflect current academic thinking about strategic alignment with regard to the public procurement process. This framework conceptualises alignment between public procurement strategies and four specific dimensions of the environment: broader political strategies, departmental strategies, the supply market and the public organisation's internal strategies.

However, despite the framework's merit of emphasising that certain strategies need to be aligned, it is unclear about how such alignment can be created in practice. This is particularly true when it comes to the operationalisation of procurement strategies. What constitutes, in practice, alignment between, say, an awarding strategy and an organisational strategy (Patrucco et al., 2017)? How can the public buyer, or sourcing team, demonstrate that their tender dossiers align with higher-level strategies? The current literature offers no answers to these questions.

This uncertainty is aggravated by the general lack of agreement in the research community on what should form part of the alignment construct. Søgaard et al. (2019) show how researchers use various interpretations of alignment. They also observed that while researchers generally rely on practitioners' perceptions, these practitioners have a somewhat tacit understanding of the alignment construct rather than adopt the procedural understanding generally assumed in the academic literature. Finally, Søgaard et al. (2019) highlight the lack of agreement on how to measure alignment. For instance, they note that some researchers measure alignment using the procurement function's knowledge of the organisation's strategic goals, whereas others measure the adaptation of procurement plans in response to changes in strategic planning (Søgaard et al., 2019).

To sum up, it is unclear how strategic alignment between procurement instruments and higher-level strategies can be created because the literature lacks both theoretical insights and knowledge of current practices in this respect.

\section{Conceptual approach}

\subsection{Operationalisation of the strategic alignment construct}

Given the lack of agreement on what should be in the strategic alignment construct, it is important to define clearly first how the construct is operationalised in the present study. Rather than using terms such as 'process strategy' and 'awarding strategy' as used by Patrucco et al. (2017), the present study employs the term 'procurement instruments' when theorising about what exactly constitutes strategic alignment at the operational level of public procurement. Previous research has similarly employed this term to refer to the methods, systems and documents used in the procurement process (Plantinga et al., 2019). Contracts, supplier selection methods and contract award systems are examples of such procurement instruments. The advantage of applying this term is that it refers to the concrete documents and texts that are actually used in a given tendering procedure, whereas a process or awarding strategy may not be written down in a document and the content that these terms refer to may be interpreted in various ways.

The present study follows the framework of Patrucco et al. (2017) in its implicit assumption that procurement instruments need to be aligned with the four dimensions of their environment. It is logical to treat both procurement strategies and procurement instruments in the same way since procurement instruments constitute the operational means to implement procurement strategies and therefore concern the same 'content of fit' (Venkatraman and Camillus, 1984).

With regard to the question of what exactly constitutes alignment between procurement instruments and higher levels of strategy, this study employs the following perspective. It views strategic alignment in terms of logically valid relationships between the reasoning and trade-off decisions behind the design of procurement instruments on the one hand and the strategies present related to the four environmental dimensions proposed by Patrucco et al. (2017) on the other. Similar to the way in which a causal map may represent a strategic plan (Bryson et al., 2004), a procurement instrument can be considered well aligned if the corresponding reasoning and trade-off decisions form clear and logically valid means-and-ends relationships with the reasoning and trade-off decisions on these four dimensions.

In addition, this study views the creation of alignment as an iterative process. In this process, instrument design features are adjusted, added or removed in correspondence with ongoing validity assessments of the relationship between the reasoning and trade-off decisions behind instrument design on the one hand and those of higher-level strategies on the other.

\subsection{Explication of procurement reasoning}

Ideally, all relevant reasoning and trade-off decisions would be documented, since this would facilitate assessment of the validity of the relationships. However, in practice, this may often not be the case. The writing down of reasoning may be incomplete or scattered across multiple formal and informal documents and therefore may be difficult to retrieve. When it comes to the reasoning that was only verbally expressed, one needs to find the involved practitioners and rely on their recollections. Finally, some parts of the reasoning may not have been expressed at all. It is therefore highly likely that in practice, parts and elements of the means-and-ends relationships will vary on an implicit-explicit scale. To enable completion and assessment, these implicit parts of the reasoning require explication.

Furthermore, the level of implicit reasoning is probably affected by the characteristics of the process by which procurement 


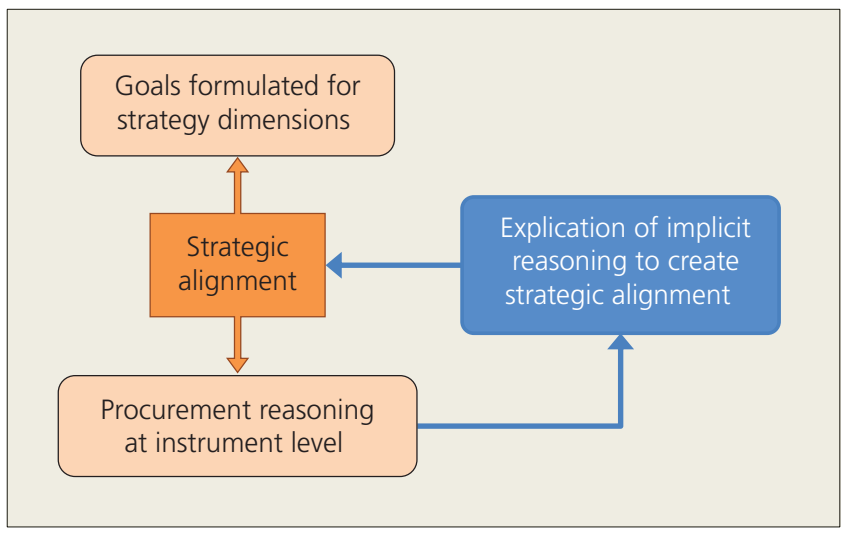

Figure 1. Analytical model

instruments are developed. Perhaps, the more intuitively and subjectively this process is run, the more implicit will be the reasoning and trade-off decisions that determine procurement instrument design (from here: procurement reasoning (PR)). Therefore, it is likely that procurement instrument development processes need a more rational approach to create favourable conditions for the PR to be explicated.

This study employs the general notion of tacit knowledge (Polanyi, 1966) to approach conceptually the explication of implicit reasoning. It has been argued that tacit knowledge and explicit knowledge form the two ends of a continuum (Nonaka and von Krogh, 2009). While purely tacit knowledge cannot by definition be turned into explicit knowledge, lesser forms of tacit knowledge can be made explicit through articulation and externalisation (Nonaka and von Krogh, 2009). This study therefore assumes that some tacit forms of reasoning, such as intuitive practitioner knowledge on the effects of a procurement instrument, need to, and can be, turned into explicit reasoning before assessing strategic alignment.

\subsection{Analytical model}

The conceptual approach elaborated earlier is summarised in the following model. A procurement instrument is considered highly strategically aligned if the PR forms logical and coherent chains of means-and-ends relationships with, ultimately, goals formulated on the four environmental dimensions: political, departmental and internal strategies plus the supply market. Ideally, the reasoning and trade-off decisions on all these levels and dimensions are documented. However, in an intuitively and subjectively run development process, the assessment and improvement of strategic alignment may be hampered by implicit reasoning. To enable assessment of strategic alignment, this implicit reasoning needs to be explicated first. Figure 1 shows the analytical model of the study.

\section{Research approach}

This research is set in the procurement department of a major public construction client in the Netherlands. The research was commissioned by the department manager in order to gain a tighter grip on the current practice in handling procurement instruments. The development of new procurement instruments was given particular attention, because the development process seemed the least manageable of all the procurement-instrumenthandling processes present in the department.

\subsection{Methodology}

To explore how the development process was enacted in the department, an action research (AR) (Azhar et al., 2010) case study was undertaken on one of the more complex procurement instrument development processes ongoing at that time. Case research is appropriate for answering how and why questions that focus on contemporary events where there is no control over behavioural issues (Yin, 2014). Case research is also appropriate for producing exemplars (Flyvbjerg, 2006) and is particularly appropriate for this research topic since there is virtually no literature on the procurement instrument development process. The external validity of case studies can be based on analytical generalisation, which refers to the logic through which case study findings can be extended to situations beyond the original case study, based on the relevance of similar theoretical concepts or principles (Yin, 2014). Analytical generalisation thus contrasts with statistical generalisation where, based on statistical inference, findings from a sample are claimed to apply to its universe.

This research has employed the single-case approach in order to study the same case at multiple points in time (Yin, 2014). This longitudinal approach was appropriate because the researchers had agreed to help improve the client's current situation through research interventions. To do so, the researchers applied the method of AR. This method is appropriate for addressing 'real-life' problems and bringing about change in specific contexts with the dual goals of making improvements and of generating knowledge (Connaughton and Weller, 2013). In the construction research community, AR has, on the one hand, been criticised in relation to its replicability, reliability, generalisability and objectivity, but on the other hand, it is also recognised for helping close the gap between theory and practice and for improving the relevance and impact of academic research through its proactive nature (Connaughton and Weller, 2013).

The present study utilised a five-step AR cycle: (a) diagnosing, (b) action planning, (c) action taking, (d) evaluating and (e) specifying learning (Azhar et al., 2010). Diagnosing amounts to identifying the primary research problem(s). Action planning establishes the target for, and approach to, change. In the actiontaking step, researchers and practitioners collaboratively intervene in the practitioner's organisation to cause certain changes. Evaluating involves determining whether the theoretical effects of the action were realised. Although, formally, specifying learning is the final step, in practice it is usually a step in an ongoing circular process (Azhar et al., 2010).

The research team consisted of four people: three researchers and the procurement officer responsible for running the development process. The latter is referred to in this paper as the procurement 
instrument developer (PID). Given that the joint interpretation of results is held to provide validity (Connaughton and Weller, 2013), the PID was actively involved in all five AR steps.

Being responsible for development progress, the PID collected and created documentation, organised meetings and reported to management. The PID involved a group of about ten peer practitioners in the development process, mainly for discussion and validation.

The researchers had the opportunity to join up with the PID in an early phase of the development process. The first author of this paper (from here: author 1) attended nine practitioner meetings organised by the PID at the procurement department during a time period of 7 months. Data were gathered by author 1 in the form of interviews of involved procurement officials, external and internal client documents (reports, memos, emails) and meeting observations. These observations were documented in field notes. Procurement officials were typically interviewed shortly after a development process meeting had taken place. The goal of these interviews was to question the meeting participants individually and compare their inputs. Interviews had a semi-structured format, using a fixed set of questions and taking the opportunity to inquire further when considered necessary. Questions primarily dealt with a participant's reasoning on the new procurement instrument and potential issues that impeded delivering such reasoning. In total, 14 interviews were held. These typically lasted $1 \mathrm{~h}$ and were audio-recorded and later transcribed and coded.

The second author took part in some of the development process meetings to gain a personal frame of reference when discussing steps in each AR cycle. The third author did not take part in these meetings in order to safeguard objectivity during the AR cycles.

Since the AR intervened in an ongoing development process and explication and linking of the reasoning were best observable during PR discussions in practitioner meetings, the AR cycles were defined by the extent to which interventions had resulted in satisfactory effects in later meetings. The AR cycles were therefore delineated by the meetings organised during the development process.

\subsection{Case description}

The development process in question concerns the development of a new qualification system (QS). Since this instrument is being developed by a public client in the Netherlands, it has to comply with the general European regulations on public procurement (Bovis, 2012) and so it is best to define it in terms of that legal framework. The European utilities directive describes a QS as an option for particular types of public clients. A QS offers the opportunity to select potential suppliers for a period of time and a certain scope of work, rather than having them requalify for each tendering procedure (article 77, directive 2014/25/EU (EC, 2014)).

In the case organisation, a PID was assigned to develop a vision for a new QS. The client's current QS was established more than
20 years ago and was used to prequalify suppliers for six segments, such as the daily maintenance of the tracks and the design and installation of train signalling systems and power supplies, which are key for the functioning of the railway system. With over 100 suppliers listed in the QS, this procurement instrument was highly relevant to the public client.

Over time, the QS had undergone some considerable changes, but recently, the department's management had decided that the current QS design should be fundamentally reconsidered. Management selected a specific PID for this task because of his extensive knowledge of the current QS.

The first stage of the procurement instrument development process was vision creation. Following management approval, the next stages would involve detailing the vision and implementing it in practice.

\section{Results}

In the past, AR papers have been criticised for not being entirely clear as to what 'interventions' (actions) were being introduced, observed, reflected on and used as a basis for a further AR cycle (Connaughton and Weller, 2013). To address these concerns, the individual steps are summarised here and elaborated below to provide clarity with regard to these interventions. In total, three AR cycles were completed before assessment of strategic alignment was achieved. The main findings from the AR cycles are the following.

- Disentangling PR from other development process aspects is needed in order to recognise PR explication as a separate activity (AR cycle 1 ).

- The subjective and fragmented nature of the PR generated impedes rational assessment of strategic alignment (AR cycle 2).

- Revising the causal map of an instrument during the procurement instrument development process provides a rational way to create strategic alignment (AR cycle 3).

\subsection{AR cycle 1: disentangling PR}

The first AR cycle was triggered by research observations in a $2 \mathrm{~h}$ meeting in which the PID presented his first ideas regarding the new QS to a small group of colleagues. Author 1 attended this meeting and then organised five separate $1 \mathrm{~h}$ interviews.

\subsubsection{Diagnosing}

Conversations during the trial meeting barely touched on PR. Most of the meeting was spent clarifying issues that involved time-consuming discussions between the PID and the participants. In total, the researchers categorised nine such issues from the meeting and the interviews.

One category of issues concerned ambiguity in the assignment to create a vision. It was observed in the meeting and in subsequent interviews that the assignment lacked clarity. Questions were raised with regard to what exactly the development process should deliver (issue 1: what is a 'vision' anyway?), what 
triggered the assignment (issue 2: why a new vision?), what is the current state (issue 3: what exactly is the current vision, and is it documented?), which problems should be solved (issue 4: on precisely which aspects is the current QS supposedly lacking?) and how urgent is the assignment (issue 5: when to deliver, and what are the consequences if delivery is late?).

Another category of issues is related to ambiguity in the organisation of the development process. This regarded current process design (issue 6: how is the process designed, what are the next steps and who is involved?) and alternative ideas for running such a process (issue 7: benchmark international QS designs?).

The final category of issues concerned practitioners' understanding of the current QS. Questions were raised about demarcation (issue 8: what exactly is part of the QS?) and performance measurement (issue 9: how is the current QS's performance assessed and how should it be assessed?).

\subsubsection{Action planning}

The authors initially hypothesised that a clear conceptual identification of PR and its role in the development process was needed. Describing process activities and the role of PR in some of these activities would help move development process ambiguities to one side and thus create time and attention for PR.

\subsubsection{Action taking}

Based on the issues identified earlier and generic schemes for design processes, author 1 developed a proposal for a generic procurement instrument development procedure. The goal of this procedure proposal was both to address the issues identified earlier and to create time and attention for explication of PR. Figure 2 summarises this procedure proposal and marks the activities where the PID needs to focus on explication of PR in particular. The proposal was discussed and approved in a workshop with the PID, members of the management team and the researchers.

\subsubsection{Evaluating}

After the workshop, the PID and the first two authors evaluated the action. Overall, it was concluded that the procedure proposal was an improvement on current practice because it distinguishes PR-related activities from activities relevant for organising the procurement instrument development process. This enables the PID to focus on PR explication and save it from drowning in process ambiguities.

\subsubsection{Specifying learning}

The development process and PR can be intertwined in an ambiguous manner. Therefore, disentangling PR from other development process aspects is needed in order to recognise PR explication as a separate activity.

\subsection{AR cycle 2: explicating PR}

The second cycle was started after a $2 \mathrm{~h}$ 'vision-sharing session' organised by the PID. Having substantially elaborated on his original ideas, his aim was now to present these as 'the vision' for the new QS and find out whether the attendees would support this vision. The PID's PR was incorporated in his presentation. Three experienced category managers and author 1 were invited to this session. Within the 2 weeks following this meeting, author 1 interviewed each of these category managers. The separate $1 \mathrm{~h}$

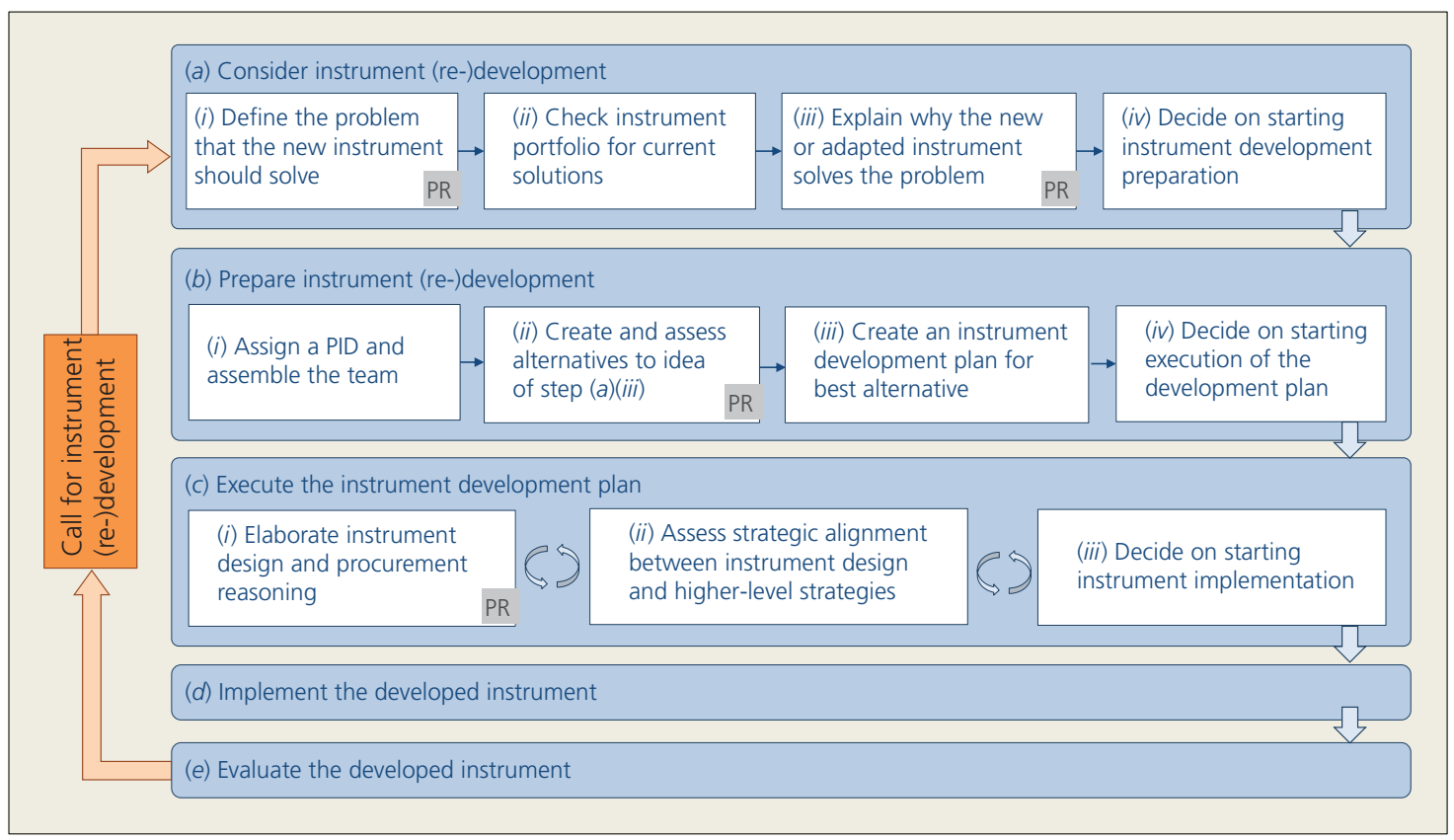

Figure 2. Summary of the proposed procedure for procurement instrument development 
interviews were intended to evaluate the meeting in general and particularly to explore each person's personal PR on the QS.

\subsubsection{Diagnosing}

The PID felt that he was not receiving sufficient feedback in the form of PR. As in AR cycle 1, discussions on other issues were consuming the meeting time. Six additional issues were identified. These were categorised as either development process issues (issue 10: more time needed to process all the information before confirming one's support of the new vision; issue 11: changed motivation for creating a new vision; issue 12: lack of clarity about the extent of personal involvement in the development process) or PR process issues (issue 13: reinvention of PR; issue 14: difficulties in articulating PR; issue 15: insufficient opportunity to develop PR).

\subsubsection{Action planning}

Author 1 and the PID agreed to invite the category managers for a second $2 \mathrm{~h}$ meeting but, this time, they would be restricted to talking only about PR in the sense of the presumed effects of the new QS design in their respective procurement categories. To illustrate the desired PR, quotes from each of the earlier interviews would be presented as examples of PR. In this way, the category managers would be shown which parts of their own words should be understood as PR.

\subsubsection{Action taking}

In the second meeting, both the PID and the authors intervened several times to urge the category managers to explicate their PR. This resulted in pieces of PR for each procurement category, such as 'I expect the new QS will decrease our supply market'. Why? 'In my category, some types of contractors will doubt whether the relatively limited amount of expected future work outweighs the investment needed to become qualified.' In turn, this gave rise to a discussion on the desired number of competitors for that particular type of contract and the expected increase in quality delivered.

\subsubsection{Evaluating}

The PID and the first and second authors evaluated the action taking. It was noted as a positive result, that this time each of the category managers had expressed their PR about the presumed effects of the vision. Further, the PR was deepened through discussion. While it was clearly not always easy to explicate one's PR, the relevance of explication became clear in this meeting. However, the generated PR came across as rather incomplete and subjectively prioritised lines of argument. Relationships with higher-level procurement strategies and ultimately the public client's strategic goals (safety, reliability, punctuality and sustainability of the rail infrastructure) were unclear or missing.

\subsubsection{Specifying learning}

While it is certainly helpful that practitioners now acknowledge the role of PR in the development process and that time has been devoted to explicate PR, the subjective and fragmented nature of the generated PR impedes rational assessment of alignment.

\subsection{AR cycle 3: creating strategic alignment}

Author 1 initiated the third AR cycle after a meeting with the procurement department's management team. Having finalised his vision on the new QS, the PID's next step was to obtain management approval. To this end, the PID organised a $2 \mathrm{~h}$ session with management representatives, some category managers and some experts on the current QS. The first two authors also attended this meeting.

\subsubsection{Diagnosing}

The presumed impact of the new vision was seen as referring to an overly complicated environment that would make it impossible to inform the management team swiftly. It was diagnosed that the PR generated so far needed more structuring and that the relationship between PR and goals needed to be more clearly established.

\subsubsection{Action planning}

It was hypothesised that causal mapping (Bryson et al., 2004) would be a helpful tool for structuring the PR and establishing relationships with goals. Since both the PID and the researchers were inexperienced with causal mapping, it was decided to try it out with only the PID initially, using only the PR generated so far. Author 1 was to make himself familiar with the causal mapping literature so that he could guide this process.

\subsubsection{Action taking}

Author 1 organised a $2 \mathrm{~h}$ session with the PID to use causal mapping as a means to assess strategic alignment. In this session, the PR behind the new vision was linked to a mix of top-level organisational goals (e.g. safety), lower-level category goals (e.g. competition) and inter-organisational goals (as described in the client's concession granted by government) and to some supply market features.

\subsubsection{Evaluating}

For a complex system such as the QS, causal mapping was seen as a useful tool for structuring PR and relating it to higher-level goals and strategies. The causal map for the new QS provided a practical means to place PR in a logical hierarchy. Similar to the causal mapping of process descriptions, going back and forth between the hierarchy of reasoning resulted in adjusted relationships and additions and reformulations of reasoning. As such, the process of creating this map also resulted in an assessment of alignment, because the hierarchically linked reasoning was validated on the logic of presumed cause-and-effect relationships while attempting to complete the causal map. This seemed an almost immediate side effect of the causal mapping process, since incomplete parts of the map may point towards potential misalignments.

\subsubsection{Specifying learning}

Causal mapping provides a practical tool for supporting the creation of strategic alignment by structuring and improving the 
Table 1. Summary of AR cycles

\begin{tabular}{|c|c|c|c|c|c|}
\hline & Diagnosis & Action planning & Action taking & Evaluating & Specifying learning \\
\hline AR cycle 1 & $\begin{array}{l}\text { Implicit process design } \\
\text { impedes explication of } \\
\text { PR }\end{array}$ & $\begin{array}{l}\text { Clarify the process design } \\
\text { in general and the role } \\
\text { of PR in particular }\end{array}$ & $\begin{array}{l}\text { Procedure } \\
\text { proposed to } \\
\text { clarify process } \\
\text { design and PR }\end{array}$ & $\begin{array}{l}\text { The procedure is } \\
\text { helpful but } \\
\text { insufficient to } \\
\text { explicate PR }\end{array}$ & $\begin{array}{l}\text { The development process and } \\
\text { PR are ambiguously } \\
\text { intertwined }\end{array}$ \\
\hline AR cycle 2 & $\begin{array}{l}\text { Explication of PR should } \\
\text { be conceptualised and } \\
\text { organised }\end{array}$ & $\begin{array}{l}\text { Dedicate meeting to just } \\
\text { PR and illustrate the } \\
\text { concept of PR }\end{array}$ & $\begin{array}{l}\text { PR explained and } \\
\text { stimulated in a } \\
\text { practitioner } \\
\text { meeting }\end{array}$ & $\begin{array}{l}\text { The generated PR } \\
\text { appears subjective, } \\
\text { incomplete and } \\
\text { difficult to link }\end{array}$ & $\begin{array}{l}\text { Generating PR requires } \\
\text { explication of PR to be } \\
\text { conceptualised, organised } \\
\text { and stimulated }\end{array}$ \\
\hline AR cycle 3 & $\begin{array}{l}\text { Complicated instrument } \\
\text { environment hinders } \\
\text { clear explication and } \\
\text { linking of PR }\end{array}$ & $\begin{array}{l}\text { Use the causal mapping } \\
\text { method to complete and } \\
\text { link PR with strategy } \\
\text { dimensions }\end{array}$ & $\begin{array}{l}\text { Causal mapping } \\
\text { applied in } \\
\text { practitioner } \\
\text { meeting }\end{array}$ & $\begin{array}{l}\text { Causal mapping helps } \\
\text { articulate, discuss, } \\
\text { link and complete } \\
\text { PR }\end{array}$ & $\begin{array}{l}\text { Alignment can be rationally } \\
\text { created by revising the causal } \\
\text { map during the development } \\
\text { process }\end{array}$ \\
\hline
\end{tabular}

PR so far generated, linking PR with other reasoning and goals and complementing the hierarchies of reasoning. The process of revising the causal map of an instrument along with the development of a procurement instrument provides a rational way to create strategic alignment.

Since this reflection answers the research question of this study, no more AR cycles were required from the academic perspective. Table 1 summarises how the AR cycles resulted in an answer to the research question.

\section{Discussion}

This study set out to explore how public clients can rationally and objectively create strategic alignment during the development of a new procurement instrument. Previous research posited that procurement instrument development was often an intuitive and subjective process (Ballesteros-Pérez et al., 2015). This was also seen in the present research, with the development process both started and shaped in an implicit manner. The majority of the 15 issues identified in the case study concern ambiguities that can be removed by explicating decisions, assumptions and facts. In this sense, the case study is exemplary (Flyvbjerg, 2006) for how the development process can be intuitively and subjectively run.

Most striking in this respect is the intuitive dealing with the strategic alignment construct. It seemed that achieving alignment was initially only intuitively striven for. Although the need to create consistency with organisational goals, regulatory frameworks and supply market characteristics appeared selfevident to the practitioners, it was unclear how they conceptualised alignment and how the development process would lead to alignment being created. This corresponds with the observation by Søgaard et al. (2019) that practitioners employ a more tacit understanding of strategic alignment than researchers do.

This intuitive and subjective way of running the development process creates space for many issues to arise, for discussions to become blurred and for participants to contribute in intuitive and fragmented ways. Most significantly, it also impeded the rational creation of strategic alignment. Creating strategic alignment is not simply a matter of putting it on the agenda; it requires knowledge, skill and involvement to produce a demonstrably rationalised and objective form of strategic alignment.

One key problem is that it is necessary to explicate PR before one can create strategic alignment, and this in itself is already difficult. Explication requires not only time to be dedicated to PR in meetings; it also requires the willingness and ability of practitioners to collectively articulate, share, discuss and combine their PRs. It seems that the more complex a procurement instrument and its context become, the more experts that are required to be involved to cover all aspects and the more collective explication of PR is needed to achieve a complete and rationalised form of PR.

Another key problem is that the generated PR needs to be linked through reasoning, and ultimately with goals, to the four environmental dimensions by Patrucco et al. (2017). In this case, this linking quickly proved complex, as there were many relationships between the instrument and its context. Here, causal mapping (Bryson et al., 2004) was found to be a helpful and practical tool for managing this complexity. It was also helpful in explicating PR and stimulating practitioners to address incomplete or illogical parts of their PR. On this basis, it appears that officials developing procurement instruments should either have the ability or avail themselves of the capability of effectively chairing meetings dedicated to explicating and linking PR.

To avoid this explication and linking of PR drowning in process issues, it is necessary to apply a clear procedural design for the entire development process. The procedure proposed in the case study can be seen as an initial attempt to break away from what is presumed to be the current widespread intuitive and subjective practice of instrument development. Given the extensive research on procedures for selecting procurement instruments (e.g. Love et al., 2012), the development of new instruments deserves much more research attention in the future. This view is also supported by the business process literature, where the identification of 'initial state processes' is recognised as the first step towards higher process maturity (e.g. Röglinger et al., 2012). The procedure 
adopted in the case study helped move the client's development process from the 'initial' stage to the 'defined' stage, thus enabling opportunities for further process improvement.

\section{Conclusions and suggestions for further research}

Strategic alignment can be created rationally and objectively during the process of developing procurement instruments by explicating and linking the reasoning behind the design of procurement instruments with the reasoning behind higher-level strategies. Here, it is crucial to organise this explication and the linking of reasoning as a central and recurring activity throughout the development process, since practitioners tend to implicitly assume alignment rather than explicitly assess and demonstrate it.

Given that the literature on procurement instrument development by public clients is scarce and that this research concerns only a single case, future research could validate the assumptions made in this study that intuitive and subjective development processes are widespread in current practice and that these processes generally include no more than implicit assessment of strategic alignment. Future research is also needed to operationalise the performance concept so that the generally assumed performance improvement associated with the creation of strategic alignment can be demonstrated and measured in practice.

\section{Acknowledgements}

This paper was originally presented in 2019 at the 35th Annual Association of Researchers in Construction Management Conference in Leeds, UK. The authors would like to thank ProRail for enabling this case study.

\section{REFERENCES}

Azhar S, Ahmad I and Sein MK (2010) Action research as a proactive research method for construction engineering and management. Journal of Construction Engineering and Management 136(1): 87-98, https://doi.org/10.1061/(ASCE)CO.1943-7862.0000081.

Baier C, Hartmann E and Moser R (2008) Strategic alignment and purchasing efficacy: an exploratory analysis of their impact on financial performance. Journal of Supply Chain Management 44(4): 36-52, https://doi.org/10.1111/j.1745-493X.2008.00071.x.

Ballesteros-Pérez P, Skitmore M, Pellicer E and González-Cruz MC (2015) Scoring rules and abnormally low bids criteria in construction tenders: a taxonomic review. Construction Management and Economics 33(4): 259-278, https://doi.org/10.1080/01446193.2015.1059951.

Bovis C (2012) EU Public Procurement Law. Edward Elgar Publishing, Cheltenham, UK.

Bryson JM, Ackermann F, Eden C and Finn CB (2004) Visible Thinking: Unlocking Causal Mapping for Practical Business Results. Wiley, Hoboken, NJ, USA.

Connaughton J and Weller S (2013) Improving collaboration in construction: an opportunity for action research. In Proceedings 29th Annual ARCOM Conference, 2-4 September 2013, Reading, UK (Smith SD and Ahiaga-Dagbui DD (eds)). Association of Researchers in Construction Management, Reading, UK, pp. 1125-1134.

Drazin R and Van de Ven AH (1985) Alternative forms of fit in contingency theory. Administrative Science Quarterly 30(4): 514-539, https://doi.org/10.2307/2392695.
EC (European Community) (2014) Directive 2014/25/EU of the European Parliament and of the Council of 26 February 2014 on procurement by entities operating in the water, energy, transport and postal services sectors and repealing Directive 2004/17/EC. Official Journal of the European Union L94/243.

Flyvbjerg B (2006) Five misunderstandings about case-study research. Qualitative Inquiry 12(2): 219-245, https://doi.org/10.1177/ 1077800405284363.

Glas AH, Schaupp M and Essig M (2017) An organizational perspective on the implementation of strategic goals in public procurement. Journal of Public Procurement 17(4): 572-605, https://doi.org/10.1108/jopp17-04-2017-b004.

Love PED, Edwards DJ, Irani Z and Sharif A (2012) Participatory action research approach to public sector procurement selection. Journal of Construction Engineering and Management 138(3): 311-322, https:// doi.org/10.1061/(ASCE)CO.1943-7862.0000440.

Meskendahl S (2010) The influence of business strategy on project portfolio management and its success - a conceptual framework. International Journal of Project Management 28(8): 807-817, https:// doi.org/10.1016/j.ijproman.2010.06.007.

Naoum SG and Egbu C (2016) Modern selection criteria for procurement methods in construction: a state-of-the-art literature review and a survey. International Journal of Managing Projects in Business 9(2): 309-336, https://doi.org/10.1108/IJMPB-09-2015-0094.

Nonaka I and von Krogh G (2009) Perspective - Tacit knowledge and knowledge conversion: controversy and advancement in organizational knowledge creation theory. Organization Science 20(3): 635-652, https://doi.org/10.1287/orsc.1080.0412.

Patrucco AS, Luzzini D, Ronchi S et al. (2017) Designing a public procurement strategy: lessons from local governments. Public Money \& Management 37(4): 269-276.

Patrucco AS, Walker H, Luzzini D and Ronchi S (2019) Which shape fits best? Designing the organizational form of local government procurement. Journal of Purchasing and Supply Management 25(3): 269-276, https://doi.org/10.1080/09540962.2017.1295727.

Plantinga H, Voordijk H and Dorée A (2019) The reasoning behind infrastructure manager's choice of procurement instruments. Engineering, Construction and Architectural Management 26(2): 303-320, https://doi.org/10.1108/ECAM-02-2018-0068.

Polanyi M (1966) The Tacit Dimension. Doubleday, New York, NY, USA.

Rodríguez-Escobar JA and González-Benito J (2017) The effect of strategic alignment on purchasing management. Management Research Review 40(11): 1175-1200, https://doi.org/10.1108/MRR-02-20170042.

Röglinger M, Pöppelbuß J and Becker J (2012) Maturity models in business process management. Business Process Management Journal 18(2): 328-346, https://doi.org/10.1108/14637151211225225.

Schoonhoven CB (1981) Problems with contingency theory: testing assumptions hidden within the language of contingency 'theory'. Administrative Science Quarterly 26(3): 349-378, https://doi.org/10. 2307/2392512.

Søgaard B, Skipworth HD, Bourlakis M, Mena C and Wilding R (2019) Facing disruptive technologies: aligning purchasing maturity to contingencies. Supply Chain Management 24(1): 147-169, https://doi. org/10.1108/SCM-03-2018-0087.

Spina G, Caniato F, Luzzini D and Ronchi S (2016) Assessing the use of external grand theories in purchasing and supply management research. Journal of Purchasing and Supply Management 22(1): 18-30, https://doi.org/10.1016/j.pursup.2015.07.001.

Venkatraman N and Camillus JC (1984) Exploring the concept of 'fit' in strategic management. Academy of Management Review 9(3): 513-525, https://doi.org/10.5465/amr.1984.4279696.

Watermeyer RB (2012) A framework for developing construction procurement strategy. Proceedings of the Institution of Civil 
Engineers - Management, Procurement and Law 165(4): 223-237, https://doi.org/10.1680/mpal.11.00014.
Yin RK (2014) Case Study Research: Design and Methods. Sage, Thousand Oaks, CA, USA.

\section{How can you contribute?}

To discuss this paper, please email up to 500 words to the editor at journals@ice.org.uk. Your contribution will be forwarded to the author(s) for a reply and, if considered appropriate by the editorial board, it will be published as discussion in a future issue of the journal.

Proceedings journals rely entirely on contributions from the civil engineering profession (and allied disciplines). Information about how to submit your paper online is available at www.icevirtuallibrary.com/page/authors, where you will also find detailed author guidelines. 